The role of radioactive iodine in the management of patients with differentiated thyroid cancer - An oncologic surgical perspective

\author{
Nixon, I. J.
}

2020-05

Nixon , I J , Shah , J P , Zafereo , M , Simo , R S , Hay , I D , Suarez , C, Zbaren , P , Rinaldo , A , Sanabria , A , Silver , C, Mäkitie , A , Vander Poorten , V , Kowalski , L P , Shaha , A R , Randolph , G W \& Ferlito , A 2020 , ' The role of radioactive iodine in the management of patients with differentiated thyroid cancer - An oncologic surgical perspective ' , European Journal of Surgical Oncology , vol. 46 , no. 5 , pp. 754-762 . https://doi.org/10.1016/j.ejso.2

http://hdl.handle.net/10138/330378

https://doi.org/10.1016/j.ejso.2020.01.010

draft

Downloaded from Helda, University of Helsinki institutional repository.

This is an electronic reprint of the original article.

This reprint may differ from the original in pagination and typographic detail.

Please cite the original version. 


\title{
The role of radioactive iodine in the management of patients with differentiated thyroid cancer - An oncologic surgical perspective ${ }^{\text {it }}$
}

\author{
I.J. Nixon ${ }^{\text {a, * }}$, J.P. Shah ${ }^{\text {b }}$, M. Zafereo ${ }^{\text {c }}$, R.S. Simo ${ }^{\text {d }}$, I.D. Hay ${ }^{\text {e }}$, C. Suárez ${ }^{\text {f, g }}$, P. Zbären ${ }^{\text {h }}$, \\ A. Rinaldo ${ }^{\mathrm{i}}$, A. Sanabria ${ }^{\mathrm{j}}$, C. Silver ${ }^{\mathrm{k}}$, A. Mäkitie ${ }^{\text {l, } \mathrm{m}, \mathrm{n}}$, V. Vander Poorten ${ }^{\circ}$, L.P. Kowalski ${ }^{\mathrm{p}}$, \\ A.R. Shaha ${ }^{\text {b }, ~ G . W . ~ R a n d o l p h ~}{ }^{\mathrm{q}}$, A. Ferlito ${ }^{\mathrm{r}}$ \\ a Department of Otolaryngology, Head and Neck Surgery, NHS Lothian, University of Edinburgh, UK \\ ${ }^{\mathrm{b}}$ Head and Neck Service, Memorial Sloan-Kettering Cancer Center, New York, NY, USA \\ ${ }^{\mathrm{c}}$ Head and Neck Surgery, MD Anderson Cancer Center, Houston, TX, USA \\ d Department of Otorhinolaryngology Head and Neck Surgery, Head, Neck and Thyroid Oncology Unit, Guy's and St Thomas' Hospital NHS Foundation Trust, \\ London, UK \\ ${ }^{\mathrm{e}}$ Division of Endocrinology and Internal Medicine, Mayo Clinic School of Medicine, Rochester, MN, USA \\ ${ }^{\mathrm{f}}$ Instituto de Investigación Sanitaria del Principado de Asturias, Oviedo, Spain \\ ${ }^{\mathrm{g}}$ Instituto Universitario de Oncología del Principado de Asturias, Universidad de Oviedo, Oviedo, Spain \\ ${ }^{\mathrm{h}}$ Department of Otorhinolaryngology, Head and Neck Surgery, University Hospital, Bern, Switzerland \\ ${ }^{\mathrm{i}}$ University of Udine School of Medicine, Udine, Italy \\ ${ }^{\mathrm{j}}$ Department of Surgery, School of Medicine, Universidad de Antioquia, Centro de Excelencia en Cirugia de Cabeza y Cuello-CEXCA, Medellin, Colombia \\ ${ }^{\mathrm{k}}$ Department of Surgery, University of Arizona College of Medicine, Phoenix, AZ, USA \\ ${ }^{1}$ Department of Otorhinolaryngology, Head and Neck Surgery, University of Helsinki and Helsinki University Hospital, Finland \\ ${ }^{\mathrm{m}}$ Research Program in Systems Oncology, Faculty of Medicine, University of Helsinki, Helsinki, Finland \\ ${ }^{\mathrm{n}}$ Division of Ear, Nose and Throat Diseases, Department of Clinical Sciences, Intervention and Technology, Karolinska Institute and Karolinska Hospital, \\ Stockholm, Sweden \\ ${ }^{\circ}$ Department of Oncology, section Head and Neck Oncology, KU Leuven, and Otorhinolaryngology, Head and Neck Surgery, University Hospitals Leuven, \\ Leuven Cancer Institute, Leuven, Belgium \\ ${ }^{\mathrm{p}}$ Department of Head and Neck Surgery and Otorhinolaryngology, A.C. Camargo Cancer Center, and Head and Neck Surgery Department, Faculty of \\ Medicine, University of Sao Paulo, São Paulo, Brazil \\ ${ }^{\mathrm{q}}$ Division of Thyroid and Parathyroid Endocrine Surgery, Department of Otolaryngology, Massachusetts Eye and Ear Infirmary, Boston, MA, USA \\ ${ }^{\mathrm{r}}$ Coordinator of the International Head and Neck Scientific Group, Padua, Italy
}

\section{A R T I C L E I N F O}

\section{Article history:}

Received 9 October 2019

Received in revised form

16 November 2019

Accepted 6 January 2020

Available online $\mathrm{xxx}$

\section{Keywords:}

Radioactive iodine

Adjuvant

Thyroid cancer

Thyroidectomy

\begin{abstract}
A B S T R A C T
With improved understanding of the biology of differentiated thyroid carcinoma its management is evolving. The approach to surgery for the primary tumour and elective nodal surgery is moving from a "one-size-fits-all" recommendation to a more personalised approach based on risk group stratification. With this selective approach to initial surgery, the indications for adjuvant radioactive iodine (RAI) therapy are also changing. This selective approach to adjuvant therapy requires understanding by the entire treatment team of the rationale for RAI, the potential for benefit, the limitations of the evidence, and the potential for side-effects.

This review considers the evidence base for the benefits of using RAI in the primary and recurrent setting as well as the side-effects and risks from RAI treatment. By considering the pros and cons of adjuvant therapy we present an oncologic surgical perspective on selection of treatment for patients, both following pre-operative diagnostic biopsy and in the setting of a post-operative diagnosis of malignancy.
\end{abstract}

๑ 2020 Elsevier Ltd, BASO The Association for Cancer Surgery, and the European Society of Surgical Oncology. All rights reserved.

\footnotetext{
* This article was written by members of the International Head and Neck Scientific Group (www.IHNSG.com).

* Corresponding author. Department of Otolaryngology, Head and Neck Surgery, Lauriston Building, Lauriston Place, Edinburgh, EH3, UK.

E-mail address: iain.nixon@nhs.net (I.J. Nixon).
} 


\section{Introduction}

Follicular cell-derived thyroid carcinoma (FCTC), when it is well differentiated, is generally an indolent disease which can be managed by surgery alone in most patients; papillary thyroid carcinoma (PTC) represents $80-85 \%$ of cases of FCTC and follicular thyroid carcinoma (FTC) typically 10-15\% [1]. Poorly differentiated and undifferentiated (anaplastic) thyroid cancer will not be discussed in this review. The need for additional postoperative therapy increases with the aggressiveness of disease. Radioactive iodine (RAI) has long been known to have a role in the management of both PTC and FTC and the goals of RAI therapy have recently been defined as ablation of normal thyroid tissue (remnant ablation), adjuvant treatment, or treatment of known disease (gross residual, locoregional or distant spread) [2].

Options for disease management teams to consider when managing PTC or FTC range from active surveillance, through conservative surgical resection or aggressive initial surgery with adjuvant RAI to the extreme end of the spectrum, i.e. therapeutic RAI, external beam radiation and targeted therapies for the most advanced cases [1]. For the majority of cases, who present with localized disease confined to the neck, controversy surrounds deciding whether the patient is a candidate for adjuvant RAI. As a bilobar resection approach (whether near-total or total thyroidectomy) is necessary to optimise RAI uptake, the decision to perform more extensive surgery is critical for the surgeon, and guides primary surgical management, with potentially significant consequences for the patient. International guidelines now outline an approach to selection of patients for RAI based on potential for oncological benefit [1-3]. However, a decision regarding the extent of surgical intervention relies not only on such treatment-related indications, but also complex aspects of the patient and their tumour which affect decision making throughout. The aim of this review is to consider the optimal approach to surgical management and will initially consider the evidence base supporting or opposing the use of adjuvant RAI.

\section{Initial experience with radioactive iodine}

RAI was first employed in the management of thyroid cancer in the 1940s when it was demonstrated that metastatic thyroid cancer concentrated iodine and in 1942 Keston et al. reported RAI use in treatment of a femoral metastasis [4]. For the next 25 years, reports of the use of RAI in the treatment of thyroid cancer were published in small series [5,6]. In 1967 Pochin [6] described RAI use in 200 patients with FCTC, "mainly with histologically differentiated and inoperable tumours" which they treated over 18 years in London. He demonstrated that RAI uptake developed in over $80 \%$ of differentiated tumours after thyroid hormone withdrawal and reported that an average of 6 RAI doses of $5550 \mathrm{MBq}$ each was required over 3 years to abolish all evidence of remaining tumour activity. Clearly all of these patients treated by Pochin would now be considered high-risk using contemporary risk stratification methods.

By the 1970s comparative series were being published. Varma et al. compared 263 patients treated in the era of I-131 to those treated prior, and found that in patients 40 years and older, death rates were significantly lower in patients treated with RAI than in those who did not receive RAI. This difference was not observed for younger patients [7]. Krisnamurthy and Blahd demonstrated that in 54 patients who achieved successful ablation, a lower death rate was observed with a mean delivered dose of $9065 \mathrm{MBq}$ [8].

In the same year, Mazzaferri el al. [9] reported outcomes for 576 PTC patients treated at US Air Force Hospitals. His series of papers not only described superior outcomes for PTC and FTC patients treated with total thyroidectomy, in contrast to less than total thyroidectomy, but also demonstrated lower postoperative recurrence rates for those patients treated with RAI [9-11]. [9-11]. In a subsequent re-analysis of the data, no improvement in recurrence rates after RAI were seen in low-risk PTC patients with tumours $<1.5 \mathrm{~cm}$ in diameter [11]. Although these papers had a wide reaching impact on the management of PTC, careful scrutiny of the original (1977) report showed that the actual number of patients treated with RAI following successful macroscopic excision of all disease was limited ( $n=33$ ), with the majority of patients having unresected nodal disease or distant metastases [12]. Despite its limitations, this 1977 paper influenced clinicians globally and promoted the use of RAI following surgery for the majority of patients with either PTC or FTC. The interplay between RAI and completeness of initial surgery was further demonstrated by the Michigan group in 1984 who found that successful RAI ablation was more difficult to achieve if a significant thyroid remnant was left behind. They recommended performing the "best possible total thyroidectomy" to aid successful remnant ablation [13].

However, not all endocrine oncologic groups agreed with the findings reported by Mazzaferri el al. The MD Anderson group reported outcomes for 706 patients with differentiated thyroid cancer (DTC) treated from the 1950s onwards. Although patients who received RAI had fewer recurrences, this did not translate into significant differences in either disease-free interval or survival benefit [14]. In 1983 Snyder et al. [15] from the Mayo Clinic reported outcomes for 69 patients with PTC or FTC who had radioiodine remnant ablation (RRA) after being initially treated with total or near total thyroidectomy. Their finding that successful RRA did not protect against locoregional recurrence, which occurred in $9 \%$ of their DTC patients, led them to conclude that RRA in low-risk DTC may represent a "questionable pursuit of an ill-defined goal" [15].

\section{Risk stratification and adjuvant radioactive iodine}

By the 1980s, the influence of prognostic factors on outcomes and the concept of risk stratification in DTC had been well established [16-19]. The Mayo Clinic group continued their detailed analyses of the impact of therapy on outcome, time and again demonstrating that, in low-risk PTC patients with MACIS scores [19] of $<6$, there was no evidence that RRA improved recurrence rates or survival after initial bilateral lobar resection with complete resection of all grossly visible disease [20-23]. In 2012, Schvartz et al. studied almost 1300 low-risk DTC patients managed over a 30 year period and found no impact on survival or disease free interval associated with RAI [24]. The lack of impact demonstrated by RAI use in low-risk cases has been supported by a number of recent systematic reviews on the subject [25-27]. However, it should be noted that much of the evidence in this field is retrospective and subject to bias. As such, not all experts agree, as highlighted in a recent joint statement from American and European Societies [28].

However, at the other end of the spectrum, for high-risk disease oncological improvements were demonstrated both retrospectively and in prospective cohort studies. In 1998, Taylor et al. in a prospective North American multicentre study reported improved recurrence and survival rates in high-risk PTC and FTC patients after RAI therapy was administered following initial total or near-total thyroidectomy [29]. Interestingly however, for PTC patients, when tall cell variants were excluded the significance was lost [29]. Similar results were demonstrated by Jonklaas et al. in a later analysis of the same National Thyroid Cancer Treatment Cooperative Study (NTCTCS) Registry cohort where improved outcomes were reported from stage II-IV patients following RAI, which were not seen for stage I patients [29,30]. In aggressive variants of DTC, such as insular and Hurthle cell carcinoma, National Cancer Data Base (NCDB) analysis has also suggested a role for RAI in reducing 
deaths from disease [31-33]. Similar databases have also been used to show a survival benefit in older patients with larger tumours, nodal metastases and M1 disease [34].

Therefore, for high-risk and low-risk patient groups, the positions are clear both for and against the routine use of RAI, respectively. However, a large group of patients present with disease considered to represent an intermediate risk. This group has proven difficult to study for a number of reasons. Firstly, outcomes are favourable with few deaths and a limited number of recurrences. Secondly, classification of intermediate-risk disease is variable between studies. The American Thyroid Association (ATA) classifies intermediate-risk disease as demonstrating microscopic extra thyroidal extension (ETE), significant nodal disease or adverse histological features [1]. However, recent data have suggested microscopic ETE and extension in to the strap muscles (the most common site) to be lower risk than previously considered [35-37], factors which had not been considered in historical studies.

Analysis of the Surveillance, Epidemiology, and End Results Program (SEER) database has shown that with huge cohorts of patients, statistically significant differences in survival for intermediate-risk patients can be demonstrated. However, with survival differences of as little as $1 \%$ in some groups and the methodological limitations of such datasets, the clinical significance of these findings has been questioned [38]. Chow et al. retrospectively demonstrated a recurrence advantage when intermediate risk patients were managed with RAI, with the greatest advantage reported in those with the most advanced nodal disease [39]. Similar findings have been shown prospectively by Jonklaas et al. [29] reporting on behalf of the NTCTCS Group. The results of this analysis are complex, however, as some patients who would now be considered as intermediate risk of recurrence (younger patients with N1 disease) were categorised as low-risk in this study, and no benefit was demonstrated in this stage I disease. In keeping with these findings, the Mayo Clinic also reported no benefit in patients with nodal disease who were categorised as low risk [40]. These inconsistent findings are recognised in systematic reviews of the subject reporting a similar number of studies which demonstrate the benefit of RAI in intermediate risk disease to those that do not [27]. It is hoped that over the coming years, the "Iodine or Not" trial from the United Kingdom, which is randomising intermediate risk patients to RAI or not following total thyroidectomy, will help clarify the position in this challenging group of patients [41].

It is important however to understand that simply the discovery of a well differentiated FCDC in a lobectomy specimen is not of necessity an indication for completion thyroidectomy. Most patients with unifocal, intrathyroidal (low-risk) tumours may be cured with unilateral lobectomy alone. The need for completion total thyroidectomy should be carefully studied, as few patients with such minimal disease will benefit from adjuvant RAI, and therefore do not require a completion thyroidectomy.

The use of RAI as an alternative to completion thyroidectomy has been reported in small case series. The concept is particularly attractive in those patients who have had a diagnostic lobectomy and are found to have high-risk malignancy on final pathology, or have positive margins or gross extra-thyroidal extension of disease which may make it unresectable [42]. Due to potential risks of completion surgery, some groups have used RAI "lobectomy" in this setting. This may be considered suitable for patients who are at extremely high risk from further surgery, following initial recurrent laryngeal nerve injury [43-46]. However, experience is limited and this is not a widely accepted practice at present. There are potential drawbacks to this approach, as the residual normal thyroid tissue will absorb much of the activity, limiting the activity absorbed by residual thyroid cancer cells.

Therefore, at present, the results of progress in addressing the question of whether RAI should be used in the management of DTC have been clarified for the most advanced cases, where its use is widely supported [47]. To some degree in the lowest-risk cases clinicians agree that there is no impact on outcome. For a large group of intermediate-risk cases however, the evidence remains conflicted (Tables 1 and 2). Given the low rates of recurrence in this group (5-20\% [1]) and the large cohort size therefore required, coupled with the prolonged follow-up necessary, it is unlikely that any oncological advantage of adjuvant RAI will ever be proven for intermediate-risk patients.

\section{What dose of adjuvant radioactive iodine?}

In addition to the debate over the need for RAI, there has also been controversy over the doses required for treatment. In 1987, Creutzig et al. reported similar rates of successful ablation using low (1100MBq) versus high dose (3700MBq) treatment [48]. Similar results were reported in a prospective randomised trial of 63 patients assigned low versus high dose treatment without any demonstrable difference in post ablation outcomes on the 6 week post-treatment scan [49]. Bal et al. also found no improved efficacy with higher doses of RAI, recommending no more than $1850 \mathrm{MBq}$ as the target dose following total thyroidectomy [50]. The same group went on, in larger prospective trials to recommend a dose between 925 and $1850 \mathrm{MBq}$ [51] and ultimately to conclude in 2012 that similar outcomes were seen with low, intermediate or high doses of RAI and that they were probably administering too much iodine in remnant ablation [52]. Rosario et al. found similar results in 2004 [53], as have many subsequent groups over the past 2 decades [54-60].

In contrast, Gawkowska-Suwinska et al. found a marginal improvement in post ablation results in 220 patients with T1b-T3 NOMO DTC treated with a higher dose of RAI, when comparing 2220MBq versus 1110MBq) [61]. Zaman et al. also found higher rates of successful ablation (60\% versus $40 \%$ ) for 40 patients treated with $3700 \mathrm{MBq}$ versus $1850 \mathrm{mBq}$ [62]. In 2012, Fallahi et al. recommended high dose (3700MBq) RAI for remnant ablation following a randomised trial of 341 patients in whom the low dose group (1110MBq) had higher rates of requiring a second dose of I131 (64\% versus 39\% successful ablation for high versus low dose respectively), resulting in higher overall activity levels being delivered and more in-patient time [63].

In 2012, the New England Journal of Medicine published two landmark trials of low- versus high-dose RAI in low-risk DTC $[64,65]$. Mallick et al. reported similar levels of post ablation success and a lower rate of adverse events for 438 patients with T1-T3 tumours treated with $1110 \mathrm{MBq}$ versus $3700 \mathrm{MBq}$ in a multicentre randomised trial in the United Kingdom [64]. Schlumberger et al. included over 700 patients with T1-2,N0-1 DTC treated at 24 French centres with $1110 \mathrm{MBq}$ versus $3700 \mathrm{MBq}$. Again, outcomes in both groups were comparable with excellent post-ablation outcomes (92\% complete ablation) with the authors concluding that the lower dose may be sufficient for ablation of remnant thyroid tissue. In an accompanying editorial Alexander and Larsen [66] noted that both RAI doses were equally effective at reducing serum $\mathrm{Tg}$ to a very low level and eliminating residual thyroid tissue, as seen on ultrasonography, and that thyroid ablation occurred even in patients with pathologically confirmed regional node involvement. They felt the results from both studies should change standard practice, but also did raise the question of whether any RAI is required for low-risk patients "since $21-59 \%$ of patients in these two studies had already met the goal of a low Tg level after thyroidectomy alone" [66].

Radioiodine remnant ablation is the term used for postoperative treatment without clear evidence of ongoing malignancy which is 
Table 1

Low, intermediate and high-risk stratification (adapted from the American Thyroid Association Guidelines [2]).

\begin{tabular}{|c|c|c|}
\hline & Papillary Carcinoma & Follicular Carcinoma \\
\hline Low Risk & $\begin{array}{l}\text { - T1-2,N0,M0 } \\
\text { - Complete resection } \\
\text { - No aggressive histology } \\
\text { - No vascular invasion } \\
\text { - Clinically N0 or }<5 \text { nodes all with less than } 2 \text { mm deposits } \\
\text { - Multifocal microcarcinoma }\end{array}$ & - $<4$ foci vascular invasion \\
\hline Intermediate Risk & $\begin{array}{l}\text { - Microscopic extra thyroidal extension } \\
\text { - Aggressive histology } \\
\text { - Vascular invasion } \\
\text { - Clinically N1 (no nodes }>3 \mathrm{~cm} \text { ) } \\
\text { - RAI-avid metastatic nodes in neck on post treatment scan }\end{array}$ & $\begin{array}{l}\text { - Microscopic extra thyroidal extension } \\
\text { - Clinically N1 (no nodes }>3 \mathrm{~cm} \text { ) } \\
\text { - RAI-avid metastatic nodes in neck on post treatment scan }\end{array}$ \\
\hline High Risk & $\begin{array}{l}\text { - Gross extra thyroidal extension } \\
\text { - Incomplete resection } \\
\text { - M1 (structural of thyroglobulin suggestive) } \\
\text { - N1 disease and node }>3 \mathrm{~cm} \\
\text { - Follicular carcinoma with }>4 \text { foci of vascular invasion }\end{array}$ & \\
\hline
\end{tabular}

Table 2

Factors related to decision to offer completion thyroidectomy for RAI following initial lobectomy.

\begin{tabular}{|c|c|c|}
\hline & Favour Completion for RAI & Favour Observation \\
\hline Age & Older & Younger \\
\hline Personality & Anxiety about recurrence & Anxiety about side effects of treatment \\
\hline Occupation & & Professional voice user \\
\hline Ultrasound & Contralateral nodular disease & Normal contralateral lobe \\
\hline Histology & $\begin{array}{l}\text { Significant lymphovascular invasion, multifocality, low volume nodal } \\
\text { disease, extra-thyroidal extension }\end{array}$ & Small volume primary, pNO disease \\
\hline Functional status & No swallowing difficulty, no contraindication to general anaesthesia & $\begin{array}{l}\text { Swallowing difficulty, contraindications to general anaesthesia, } \\
\text { challenging initial surgery }\end{array}$ \\
\hline
\end{tabular}

designed to eliminate thyroid bed gland remnants which may persist after total thyroidectomy and may also serve to stage other disease sites not recognised at first surgery [28]. Thyroid bed uptake is nearly universal after even expert total thyroidectomy and a classification system has been generated to describe its pattern [67].

These results suggest therefore that there is likely little benefit in increasing doses of RAI in patients treated for low or intermediate-risk disease. Whether low dose is as good as no dose is a question that remains to be answered [41]. At present one new multicentric trial (IoN) in the United Kingdom is being carried out to address this question [41].

\section{Radioactive iodine for recurrent differentiated thyroid cancer}

As stated above, evidence supporting the use of RAI in the primary setting is of low quality and conflicted for many patient groups. Unfortunately, there is even less evidence in the setting of recurrent disease [68]. When locoregional recurrence is structurally identified, surgery is first in the hierarchy for treatment [1]. Following surgery, in the absence of distant metastases, there is little evidence to support RAI.

Hung et al. reported no difference in outcome for 102 patients treated for recurrent PTC with or without RAI in long-term followup [69]. Similar findings were reported by Yim et al. who limited their analysis to PTC patients with a detectable stimulated Tg level following re-operative surgery [70].

In patients who have a rising serum thyroglobulin $(\mathrm{Tg})$ level but an absence of structurally evident recurrent disease the role of "empiric" RAI is unclear. It can be used to identify sites of disease or in an attempt to reduce Tg levels. However, such an approach has not been shown to result in improved survival. Consequently, the ATA guidelines [2] do not recommend such an approach, but recommend consideration of RAI in this setting only when the $\mathrm{Tg}$ levels are rapidly rising. They highlight the fact that this is a weak recommendation based on low-quality evidence [1].

In the absence of strong data on which to base decisions, again treatment teams must consider a number of variables. In low-risk patients who manifest disease in the contralateral lobe following initial thyroid lobectomy, simple completion thyroidectomy may be sufficient. For those patients who develop high volume regional recurrence, surgical excision can be followed with assessment of serum $\mathrm{Tg}$ on throxine suppressive therapy.

\section{Side effects of radioactive iodine}

Although RAI has significantly less morbidity than external beam radiotherapy, it is not without side effects. These are dose related and expressed by the additional tissues which concentrate iodine, namely salivary and lacrimal glands [71-73].

Some patients complain of acute taste disturbance, and chronic dry eyes and a dry mouth, which contributes to difficulty in swallowing $[72,74]$. RAI treatment is associated with increased rates of sialadenitis [75] which in turn can have a significant impact on quality of life [76,77]. Indeed there is a reported $20 \%$ rate of dysfunctional salivary glands five years following RRA [78]. Symptoms of obstructive sialadenitis following RAI can currently be helped by sialendoscopic dilatation, rinsing and corticosteroid injection, a therapeutic option that many thyroid oncologists are unaware of [79].

In addition, there is a reported slightly increased risk of secondary haematological and salivary malignancy in patients who have received increasing doses of RAI, although this is unlikely to impact decisions at an individual level [80-82].

Therefore, the side-effects of RAI are both acute and long term. Although relatively mild in comparison with those related to external beam radiation, the chronic effects remain problematic in a group of patients who can expect long-term survival. 


\section{The current situation}

Despite conflicting evidence, guidelines on the management of DTC have attempted to provide a consensus approach. In 2009 the ATA guidelines recognised the conflicting data but recommended RAI for all high-risk patients and selected patients with $1-4 \mathrm{~cm}$ tumours and any high-risk feature. RAI was routinely recommended for high-risk patients with macroscopic ETE or significant regional or distant metastases. Microcarcinomas $(<1 \mathrm{~cm})$ were recommended not to receive RAI [83]. A similar approach was adopted in the UK with a recommendation to consider RAI in all cases other than classical micropapillary carcinoma in the British Thyroid Association (BTA) Guidelines [2]. In the 2015 updated ATA guidelines, a slight move away from an almost universal recommendation for RAI has been seen. The ATA guidelines now do not recommend RAI in low risk cases but consider its use in intermediate risk cases, particularly as risk factors such as advanced age and nodal burden increase [1]. However, mainland European groups have not endorsed such a move, pointing to the lack of prospective evidence to support it $[28,84,85]$.

Given the conflicting evidence, combined with general support for RAI in most cases provided by powerful international guideline statements, it is hardly surprising that rates of RAI have been rising. Whereas in the 1990s around 40\% of patients with tumours over $1 \mathrm{~cm}$ received RAI in the USA this had risen to over $60 \%$ by 2008 [86]. However, there is some suggestion that rates may now be starting to fall for lower-risk patients in the USA [87]. Within these findings there was significant heterogeneity of approach based on both patient and clinician factors suggesting continued uncertainty for many involved in this field.

Although exact causes for this variation in practice are unclear, they are likely to be influenced by multiple factors. The environment of clinical practice has been shown to be critical with highvolume centres more commonly recommending RAI [86]. However, approaches to imaging and pathological processing of surgical specimens have also evolved over the decades. There is an everincreasing level of scrutiny applied to each case in order to identify evidence of higher risk features such as previously occult nodal disease on ultrasound scan, and adverse histological features on pathology. The increase in frequency of prophylactic central neck dissection has produced a stage migration, that also induces the use of more RAI. Such an approach leads to an increasing number of patients identified as having higher-risk features which further, encourage treatment intensification [88].

\section{Radioactive iodine and the surgeon}

When considering the initial approach to DTC, the surgeon must consider a number of factors. Initial investigations may clearly identify patients who should or should not receive RAI and must therefore be dealt with appropriately. Examples would include a proven intra-thyroidal carcinoma without regional or distant disease. Such patients do not benefit from RAI and do not require total thyroidectomy to facilitate adjuvant therapy. In contrast, patients with significant nodal disease, distant disease or gross posterior macroscopic extra-thyroidal extension will require RAI and should undergo total thyroidectomy [1,2,89].

For the majority of patients, however, the situation is less clear and an individualised approach is recommended by guidelines. It is now well recognised that for patients with intrathyroidal disease, in the absence of high-volume nodal disease, distant disease or posterior gross extra-thyroidal extension [37], outcomes are excellent irrespective of whether or not adjuvant RAI is used. Selecting patients for RAI based on pre-operative staging may therefore not be possible. A $2 \mathrm{~cm}$ cytologically proven PTC without evidence of regional disease may, on surgical pathology prove to have significant lymphovascular invasion or adverse histological features which would prompt consideration of RAI. In contrast, for a classic papillary thyroid carcinoma without such features, treatment with lobectomy alone may be sufficient.

For many patients then, the surgeon needs to consider a variety of non-cancer factors prior to intervention. For example, is there a background of multinodular disease? If there is, particularly if these are not all ultrasonically benign in appearance, consideration should be given to total thyroidectomy versus lobectomy. Is there a reason to consider the patient particularly vulnerable to recurrent laryngeal nerve injury? Professional voice users, patients with preexisting nerve palsies or those with an unsafe swallow prior to intervention may be more suitable for lobectomy rather than total thyroidectomy. For clinicians practicing in areas of the world where ready supplies of supplements such as calcium and vitamin D are not easily obtainable, a more conservative approach may be favoured to avoid long-term complications associated with a lack of supplementation [90]. Based on these clinical factors, in addition to the initial pre-operative clinical tumour staging, the surgeon will then provide a surgical specimen of either total thyroidectomy or lobectomy. Analysis of the tumour within will then dictate further management. Of course, discussion as to the extent of thyroidectomy with a clinical endocrinologist would be important as he/she will likely contribute significantly as part of a multi-disciplinary team in the overall case management, particularly in long-term postoperative follow-up.

When a total thyroidectomy has been performed, the patient is in a position to receive an ablative dose of RAI if indicated. This is particularly important if the operation was a sub-total thyroidectomy, where RAI was historically used for thyroid remnant ablation to facilitate follow up. It is therefore crucial that, when a total thyroidectomy is contemplated, it should be a "true extra capsular total thyroidectomy", leaving no thyroid tissue behind, thus avoiding the need for "remnant ablation". Such an approach often renders the Tg level undetectable without the need for RAI to ablate residual normal tissue in the hope of achieving an undetectable $\mathrm{Tg}$. Consideration of pathological details including tumour size, adverse histology, associated nodal metastases and clinical findings in the operating room will all contribute to the multidisciplinary decision regarding the need for RAI therapy, not just remnant ablation. Many patients with thyroid cancer have significant anxiety regarding the disease [91-93], despite the excellent outcomes and the threshold for administering adjuvant RAI is correspondingly low.

If thyroid lobectomy has been performed, a similar process of consideration of the pathology should be performed. At present, international guidelines make recommendations regarding indications for RAI based on oncological factors alone. The current ATA guideline for example recommends completion thyroidectomy when a total thyroidectomy would have been recommended if the diagnosis had been available prior to initial therapy [1]. However, this is an oversimplification of the situation at the point of considering further surgery.

In contrast to the patient who underwent total thyroidectomy, adjuvant RAI will require a readmission for completion thyroidectomy. It has been well demonstrated that this procedure rarely, if ever, results in additional primary disease risk factors being identified other than previously occult small volume multifocal disease [94,95]. Therefore, clinicians should recognise that this procedure is only performed to facilitate RAI. The risks of completion thyroidectomy are not insignificant with long-term complications recorded in up to $10 \%$ of cases [96,97]. Such an approach should only be recommended if the management team consider the benefit of RAI to exceed the inconvenience and risk of further admission for 


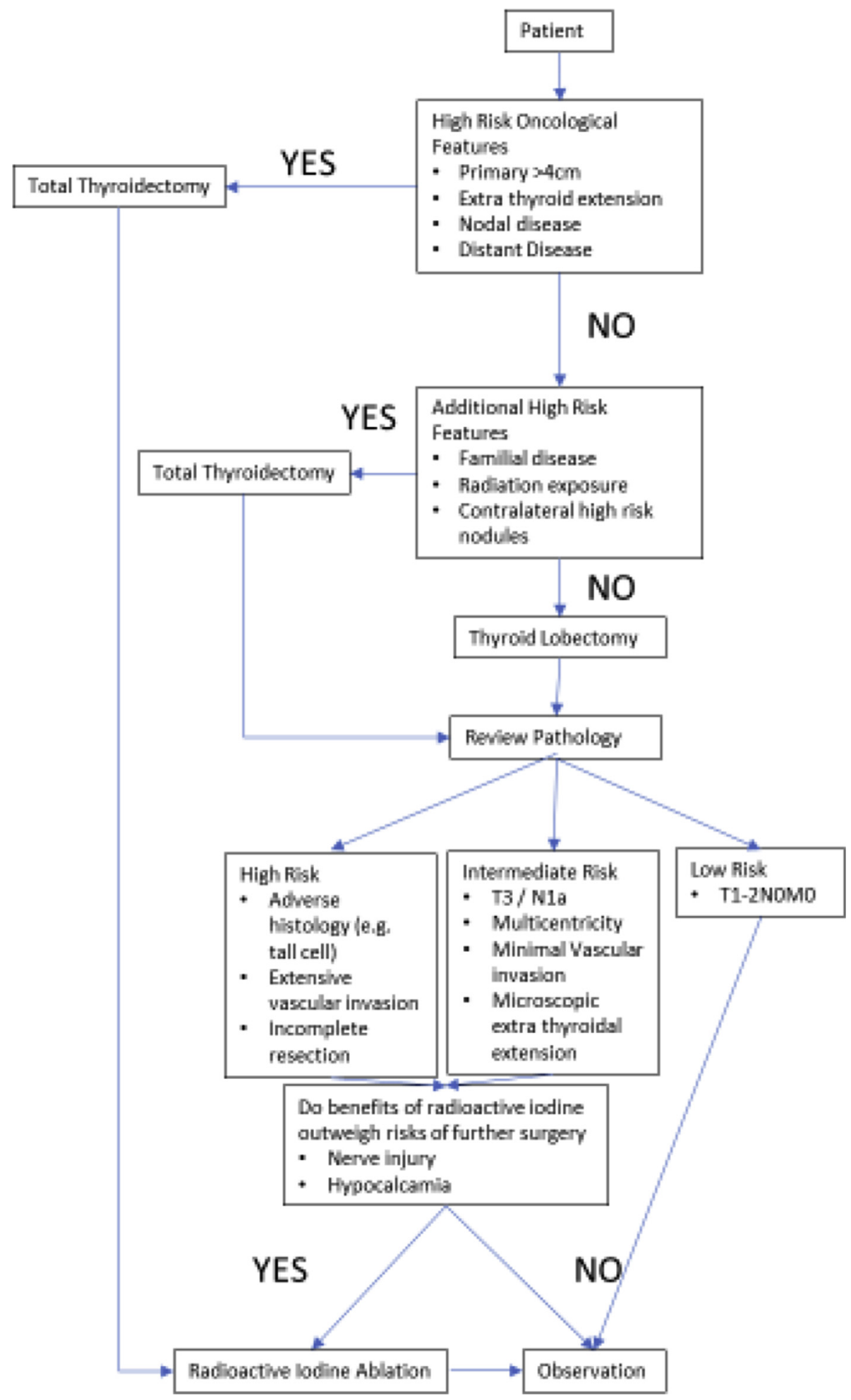

Fig. 1. Flow chart for surgical planning in differentiated thyroid cancer

surgery and then radiation and the associated long-term side effects. In practice this can be a difficult estimate to make. For lesions which demonstrate widely accepted high risk features such as tall cell variant PTC or gross extra-thyroidal extension, RAI will be indicated. For low-risk lesions without any adverse features, no further therapy is required. A framework for considering the situation following treatment without RAI based on imaging and serum
$\mathrm{Tg}$ levels in the post-surgical setting has been reported by Momesso et al. [98].

Many patients, however will have disease which is difficult to risk stratify. The presence of multifocality for example, uncertainty regarding lymphovascular invasion, small volume incidentally excised metastatic nodes or the presence of microscopic extra thyroidal extension are all risk factors which were not part of the 
original risk stratification systems but are now routinely reported. For these cases the surgeon must recognise not only the oncological uncertainty regarding the importance of these factors but also more subtle features of the patient. These will include age, the patient's personality, occupation and pre- and post-operative functional status. In addition, findings in the operating room may influence the recommendation for further surgery. In lower risk cases where surgical anatomy or physiological fitness made a case challenging, the risk of surgery is higher and may outweigh the potential benefit of adjuvant RAI (Table 2).

Brief mention of the regional lymphatics should also be made. Although the role of therapeutic neck dissection is generally accepted, that of elective surgery remains highly controversial. In the setting of selection of patients for RAI, some groups recommend elective staging of the neck in order to more accurately identify those patients who may benefit from RAI [88]. This practice identifies occult central neck disease in around one third of patients. These patients are then considered for RAI treatment based on nodal factors rather than primary disease features alone. However, such an approach has never been shown to be beneficial in terms of recurrence or survival and many groups who choose to leave such cNO necks undissected do so without any evidence of adverse outcome for their patient groups [99]. Clinicians who choose this approach to treatment should understand that, although they may demonstrate pNO disease in many patients and thereby reduce pressure to consider adjuvant RAI, they will also upstage a significant number of patients with small volume nodal disease for whom most teams will feel compelled to recommend further therapy without clear evidence of benefit.

The surgeon factor must also be considered. The relationship between surgical volume and complications is clear [100], but the relationship with complete thyroidectomy is poorly explored. The definition of total thyroidectomy is heterogenous, and some surgeons leave a small piece of thyroid gland near Berry's ligament or the upper poles in order to protect the recurrent laryngeal nerve or the parathyroid glands. Surgeons who perform this type of surgery will experience a higher post-operative serum $\mathrm{Tg}$ level in their patients. In some practices, it is assumed that RAI will compensate for this surgical approach; however, it may partially explain differences between rates of use of RAI.

Finally, the patient's wishes must be considered. Some patients press to receive RAI under the assumption that it will offer an advantage. In many practices, this pressure is hard to manage and some treatment teams may feel obliged to offer RAI even when not fully convinced of its oncological benefit.

\section{Conclusion}

In common with many aspects of the management of patients with DTC, the role of adjuvant RAI is complex and hindered by a significant amount of low-quality evidence. Early evidence demonstrated the potential that RAI had in treating the most advanced thyroid cancers. In the middle of the 20th century RAI became the standard of care for the majority of cases. However, the advent of risk stratification allowed identification of low-risk groups with little to gain from adjuvant therapy and high-risk groups who gained the most. Most recently, high-quality prospective clinical trials are demonstrating a reducing role for radioactive iodine, limiting its use to higher-risk cases. This decrease in use of routine RAI also withdraws one of the former reasons for total thyroidectomy (to facilitate RAI) and dovetails with our increasing awareness of lobectomy as an adequate initial treatment for patients with smaller tumours without extrathyroidal extension or clinically apparent nodal disease. It is critical therefore that the modern thyroid surgeon appreciates patient, tumour and background thyroid-related factors which will influence decisions regarding initial surgical therapy (Fig. 1). By carefully balancing the information available at the pre-surgical, peri-operative and post-operative stages, the surgeon can provide personalised recommendations which aim to optimise both oncological and functional outcomes for patients with DTC.

\section{Declaration of competing interest}

The authors have no conflicts of interest to declar.

\section{References}

[1] Haugen BR, Alexander EK, Bible KC, et al. American thyroid association management guidelines for adult patients with thyroid nodules and differentiated thyroid cancer: the American thyroid association guidelines task Force on thyroid nodules and differentiated thyroid cancer. Thyroid 2015;26: 1-133. official journal of the American Thyroid Association 2016.

[2] Perros P, Boelaert K, Colley S, et al. Guidelines for the management of thyroid cancer. Clin Endocrinol 2014;81(Suppl 1):1-122.

[3] Pacini F, Basolo F, Bellantone R, et al. Italian consensus on diagnosis and treatment of differentiated thyroid cancer: joint statements of six Italian societies. J Endocrinol Investig 2018;41:849-76.

[4] Keston AS, Ball RP, Frantz VK, et al. Storage of radioactive iodine in a metastasis from thyroid carcinoma. Science 1942;95:362-3.

[5] Hilton G, Cunningham RM, Billion H, et al. Radioiodine therapy of thyroid carcinoma. Acta radiologica Supplementum 1954;116:316-22.

[6] Goolden AW, Davey JB. The ablation of normal thyroid tissue with iodine 131. Br J Radiol 1963;36:340-5.

[7] Varma VM, Beierwaltes WH, Nofal MM, et al. Treatment of thyroid cancer. Death rates after surgery and after surgery followed by sodium iodide I-131. Jama 1970;214:1437-42.

[8] Krishnamurthy GT, Blahd WH. Radioiodine I-31 therapy in the management of thyroid cancer. A prospective study. Cancer 1977;40:195-202.

[9] Mazzaferri EL, Young RL, Oertel JE, et al. Papillary thyroid carcinoma: the impact of therapy in 576 patients. Medicine 1977;56:171-96.

[10] Young RL, Mazzaferri EL, Rahe AJ, et al. Pure follicular thyroid carcinoma: impact of therapy in 214 patients. J. Nucl. Med. 1980;21:733-7. official publication, Society of Nuclear Medicine.

[11] Mazzaferri EL, Young RL. Papillary thyroid carcinoma: a 10 year follow-up report of the impact of therapy in 576 patients. Am J Med 1981;70:511-8.

[12] Hay ID. Selective use of radioactive iodine in the postoperative management of patients with papillary and follicular thyroid carcinoma. J Surg Oncol 2006;94:692-700.

[13] Beierwaltes WH, Rabbani R, Dmuchowski C, et al. An analysis of "ablation of thyroid remnants" with I-131 in 511 patients from 1947-1984: experience at University of Michigan. J. Nucl. Med. 1984;25:1287-93. official publication, Society of Nuclear Medicine.

[14] Samaan NA, Maheshwari YK, Nader S, et al. Impact of therapy for differentiated carcinoma of the thyroid: an analysis of 706 cases. J Clin Endocrinol Metab 1983;56:1131-8.

[15] Snyder J, Gorman C, Scanlon P. Thyroid remnant ablation: questionable pursuit of an ill-defined goal. J. Nucl. Med. 1983;24:659-65. official publication, Society of Nuclear Medicine.

[16] Shah JP, Loree TR, Dharker D, et al. Prognostic factors in differentiated carcinoma of the thyroid gland. Am J Surg 1992;164:658-61.

[17] Byar DP, Green SB, Dor P, et al. A prognostic index for thyroid carcinoma. A study of the E.O.R.T.C. Thyroid Cancer Cooperative Group. Eur J Cancer 1979; $15: 1033-41$.

[18] Cady B, Rossi R. An expanded view of risk-group definition in differentiated thyroid carcinoma. Surgery 1988;104:947-53.

[19] Hay ID, Bergstralh EJ, Goellner JR, et al. Predicting outcome in papillary thyroid carcinoma: development of a reliable prognostic scoring system in a cohort of 1779 patients surgically treated at one institution during 1940 through 1989. Surgery 1993;114:1050-7. discussion 7-8.

[20] Hay ID. Papillary thyroid carcinoma. Endocrinol Metab Clin N Am 1990;19: $545-76$.

[21] Hay ID, Grant CS, van Heerden JA, et al. Papillary thyroid microcarcinoma: a study of 535 cases observed in a 50-year period. Surgery 1992;112:1139-46. discussion 46-7.

[22] Hay ID, Grant CS, Bergstralh EJ, et al. Unilateral total lobectomy: is it sufficient surgical treatment for patients with AMES low-risk papillary thyroid carcinoma? Surgery 1998;124:958-64. discussion 64-6.

[23] Hay ID, McConahey WM, Goellner JR. Managing patients with papillary thyroid carcinoma: insights gained from the Mayo Clinic's experience of treating 2,512 consecutive patients during 1940 through 2000. Trans Am Clin Climatol Assoc 2002;113:241-60.

[24] Schvartz C, Bonnetain F, Dabakuyo S, et al. Impact on overall survival of radioactive iodine in low-risk differentiated thyroid cancer patients. J Clin Endocrinol Metab 2012;97:1526-35.

[25] Sacks W, Fung CH, Chang JT, et al. The effectiveness of radioactive iodine for 
treatment of low-risk thyroid cancer: a systematic analysis of the peerreviewed literature from 1966 to April 2008. Thyroid 2010;20:1235-45. official journal of the American Thyroid Association.

[26] Sawka AM, Brierley JD, Tsang RW, et al. An updated systematic review and commentary examining the effectiveness of radioactive iodine remnant ablation in well-differentiated thyroid cancer. Endocrinol Metab Clin N Am 2008;37:457-80 [x].

[27] Lamartina L, Durante C, Filetti S, et al. Low-risk differentiated thyroid cancer and radioiodine remnant ablation: a systematic review of the literature. J Clin Endocrinol Metab 2015;100:1748-61.

[28] Tuttle RM, Ahuja S, Avram AM, et al. Controversies, consensus, and collaboration in the use of (131)I therapy in differentiated thyroid cancer: a joint statement from the American thyroid association, the European association of nuclear medicine, the society of nuclear medicine and molecular imaging, and the European thyroid association. Thyroid 2019;29:461-70. official journal of the American Thyroid Association.

[29] Jonklaas J, Sarlis NJ, Litofsky D, et al. Outcomes of patients with differentiated thyroid carcinoma following initial therapy. Thyroid 2006;16:1229-42. official journal of the American Thyroid Association.

[30] Jonklaas J, Cooper DS, Ain KB, et al. Radioiodine therapy in patients with stage I differentiated thyroid cancer. Thyroid 2010;20:1423-4. official journal of the American Thyroid Association.

[31] Kazaure HS, Roman SA, Sosa JA. Aggressive variants of papillary thyroid cancer: incidence, characteristics and predictors of survival among 43,738 patients. Ann Surg Oncol 2012;19:1874-80.

[32] Kazaure HS, Roman SA, Sosa JA. Insular thyroid cancer: a population-level analysis of patient characteristics and predictors of survival. Cancer 2012;118:3260-7.

[33] Jillard CL, Youngwirth L, Scheri RP, et al. Radioactive iodine treatment is associated with improved survival for patients with Hurthle cell carcinoma. Thyroid 2016;26:959-64. official journal of the American Thyroid Association.

[34] Podnos YD, Smith DD, Wagman LD, et al. Survival in patients with papillary thyroid cancer is not affected by the use of radioactive isotope. J Surg Oncol 2007;96:3-7.

[35] Nixon IJ, Ganly I, Patel S, et al. The impact of microscopic extrathyroid extension on outcome in patients with clinical T1 and T2 well-differentiated thyroid cancer. Surgery 2011;150:1242-9.

[36] Tam S, Amit M, Boonsripitayanon M, et al. Effect of tumor size and minimal extrathyroidal extension in patients with differentiated thyroid cancer. Thyroid 2018;28:982-90. official journal of the American Thyroid Association.

[37] Amit M, Boonsripitayanon M, Goepfert RP, et al. Extrathyroidal extension: does strap muscle invasion alone influence recurrence and survival in patients with differentiated thyroid cancer? Ann Surg Oncol 2018;25:3380-8.

[38] Ruel E, Thomas S, Dinan M, et al. Adjuvant radioactive iodine therapy is associated with improved survival for patients with intermediate-risk papillary thyroid cancer. J Clin Endocrinol Metab 2015:100:1529-36.

[39] Chow SM, Yau S, Kwan CK, et al. Local and regional control in patients with papillary thyroid carcinoma: specific indications of external radiotherapy and radioactive iodine according to $\mathrm{T}$ and $\mathrm{N}$ categories in AJCC 6th edition. Endocr Relat Cancer 2006;13:1159-72.

[40] Hay ID, Thompson GB, Grant CS, et al. Papillary thyroid carcinoma managed at the Mayo Clinic during six decades (1940-1999): temporal trends in initial therapy and long-term outcome in 2444 consecutively treated patients. World J Surg 2002;26:879-85.

[41] Mallick U, Harmer C, Hackshaw A, et al. Iodine or Not (IoN) for low-risk differentiated thyroid cancer: the next UK National Cancer Research Network randomised trial following HiLo. Clinical oncology, 24. Royal College of Radiologists (Great Britain); 2012. p. 159-61.

[42] Barbesino G, Goldfarb M, Parangi S, et al. Thyroid lobe ablation with radioactive iodine as an alternative to completion thyroidectomy after hemithyroidectomy in patients with follicular thyroid carcinoma: long-term follow-up. Thyroid 2012;22:369-76. official journal of the American Thyroid Association.

[43] Kiernan CM, Parikh AA, Parks LL, et al. Use of radioiodine after thyroid lobectomy in patients with differentiated thyroid cancer: does it change outcomes? J Am Coll Surg 2015;220:617-25.

[44] Hoyes KP, Owens SE, Millns MM, et al. Differentiated thyroid cancer: radioiodine following lobectomy - a clinical feasibility study. Nucl Med Commun 2004;25:245-51.

[45] Allan E, Owens SE, Waller ML. Differentiated thyroid cancer: lobectomy and radioiodine, a treatment suitable for all cases? Nucl Med Commun 1999;20: 983-9.

[46] Randolph GW, Daniels GH. Radioactive iodine lobe ablation as an alternative to completion thyroidectomy for follicular carcinoma of the thyroid. Thyroid 2002;12:989-96. official journal of the American Thyroid Association.

[47] Orosco RK, Hussain T, Noel JE, Chang DC, Dosiou C, Mittra E, et al. Radioactive iodine in differentiated thyroid cancer: a national database perspective. Endocr Relat Cancer 2019;26(10):795-802. https://doi.org/10.1530/ERC-190292.

[48] Creutzig H. High or low dose radioiodine ablation of thyroid remnants? Eur J Nucl Med 1987:12:500-2.

[49] Johansen K, Woodhouse NJ, Odugbesan O. Comparison of $1073 \mathrm{MBq}$ and $3700 \mathrm{MBq}$ iodine-131 in postoperative ablation of residual thyroid tissue in patients with differentiated thyroid cancer. J. Nucl. Med. 1991;32:252-4. official publication, Society of Nuclear Medicine.

[50] Bal C, Padhy AK, Jana S, et al. Prospective randomized clinical trial to evaluate the optimal dose of 131 I for remnant ablation in patients with differentiated thyroid carcinoma. Cancer 1996;77:2574-80.

[51] Bal CS, Kumar A, Pant GS. Radioiodine dose for remnant ablation in differentiated thyroid carcinoma: a randomized clinical trial in 509 patients. J Clin Endocrinol Metab 2004;89:1666-73.

[52] Bal C, Chandra P, Kumar A, et al. A randomized equivalence trial to determine the optimum dose of iodine-131 for remnant ablation in differentiated thyroid cancer. Nucl Med Commun 2012;33:1039-47.

[53] Rosario PW, Reis JS, Barroso AL, et al. Efficacy of low and high 131I doses for thyroid remnant ablation in patients with differentiated thyroid carcinoma based on post-operative cervical uptake. Nucl Med Commun 2004;25: 1077-81.

[54] Kukulska A, Krajewska J, Roskosz J, et al. [Optimization of 131I ablation in patients with differentiated thyroid carcinoma: comparison of early outcomes of treatment with $100 \mathrm{mCi}$ versus $60 \mathrm{mCi}$. Endokrynol Pol 2006;57: 374-9.

[55] Pilli T, Brianzoni E, Capoccetti F, et al. A comparison of 1850 (50 mCi) and $3700 \mathrm{MBq}(100 \mathrm{mCi})$ 131-iodine administered doses for recombinant thyrotropin-stimulated postoperative thyroid remnant ablation in differentiated thyroid cancer. J Clin Endocrinol Metab 2007:92:3542-6.

[56] Maenpaa HO, Heikkonen J, Vaalavirta L, et al. Low vs. high radioiodine activity to ablate the thyroid after thyroidectomy for cancer: a randomized study. PLoS One 2008;3:e1885.

[57] Caglar M, Bozkurt FM, Akca CK, et al. Comparison of 800 and $3700 \mathrm{MB}$ iodine-131 for the postoperative ablation of thyroid remnant in patients with low-risk differentiated thyroid cancer. Nucl Med Commun 2012;33 $268-74$.

[58] Zhang Y, Liang J, Yang X, et al. Low-dose radioiodine ablation in differentiated thyroid cancer with macroscopic extrathyroidal extension and low level of preablative-stimulated thyroglobulin. Nucl Med Commun 2015;36:553-9.

[59] Ma C, Feng F, Wang S, et al. Chinese data of efficacy of low- and high-dose iodine-131 for the ablation of thyroid remnant. Thyroid 2017;27:832-7. official journal of the American Thyroid Association.

[60] Ou Y, Huang R, Li L. Low- and high-dose radioiodine therapy for low-/intermediate-risk differentiated thyroid cancer: a preliminary clinical trial. Ann Nucl Med 2017;31:71-83.

[61] Gawkowska-Suwinska M, Turska M, Roskosz J, et al. Early evaluation of treatment effectiveness using $131 \mathrm{I}$ iodine radiotherapy in patients with differentiated thyroid cancer. Wiad. Lek. 2001;54(Suppl 1):278-88. Warsaw, Poland : 1960.

[62] Zaman M, Toor R, Kamal S, et al. A randomized clinical trial comparing 50mC and $100 \mathrm{mCi}$ of iodine-131 for ablation of differentiated thyroid cancers. JPMA (J Pak Med Assoc) 2006;56:353-6.

[63] Fallahi B, Beiki D, Takavar A, et al. Low versus high radioiodine dose in postoperative ablation of residual thyroid tissue in patients with differentiated thyroid carcinoma: a large randomized clinical trial. Nucl Med Commun 2012;33:275-82.

[64] Mallick U, Harmer C, Yap B, et al. Ablation with low-dose radioiodine and thyrotropin alfa in thyroid cancer. N Engl J Med 2012;366:1674-85.

[65] Schlumberger M, Catargi B, Borget I, et al. Strategies of radioiodine ablation in patients with low-risk thyroid cancer. N Engl J Med 2012;366:1663-73.

[66] Schlumberger M, Catargi B, Borget I, et al. Strategies of radioiodine ablation in patients with low-risk thyroid cancer. N Engl J Med 2012;366:1663-73.

[67] Zeuren R, Biagini A, Grewal RK, et al. RAI thyroid bed uptake after tota thyroidectomy: a novel SPECT-CT anatomic classification system. The Laryngoscope 2015;125:2417-24.

[68] Rosario PW, Mourao GF, Siman TL, et al. Adjuvant therapy with 131-iodine in patients with elevated serum thyroglobulin after reoperation due to papillary thyroid carcinoma lymph node metastases. Endocrine 2015:49:279-82.

[69] Hung ML, Wu JX, Li N, et al. Association of radioactive iodine administration after reoperation with outcomes among patients with recurrent or persistent papillary thyroid cancer. JAMA surgery 2018:153:1098-104.

[70] Yim JH, Kim WB, Kim EY, et al. Adjuvant radioactive therapy after reoperation for locoregionally recurrent papillary thyroid cancer in patients who initially underwent total thyroidectomy and high-dose remnant ablation. J Clin Endocrinol Metab 2011:96:3695-700.

[71] Alexander C, Bader JB, Schaefer A, et al. Intermediate and long-term side effects of high-dose radioiodine therapy for thyroid carcinoma. J Nucl Med 1998:39:1551-4.

[72] Almeida JP, Sanabria AE, Lima EN, et al. Late side effects of radioactive iodine on salivary gland function in patients with thyroid cancer. Head Neck 2011;33:686-90.

[73] Kloos RT, Duvuuri V, Jhiang SM, et al. Nasolacrimal drainage system obstruction from radioactive iodine therapy for thyroid carcinoma. J Clin Endocrinol Metab 2002;87:5817-20.

[74] Klein Hesselink EN, Brouwers AH, de Jong JR, et al. Effects of radioiodine treatment on salivary gland function in patients with differentiated thyroid carcinoma: a prospective study. J. Nucl. Med. 2016;57:1685-91. official publication, Society of Nuclear Medicine.

[75] Dingle IF, Mishoe AE, Nguyen SA, et al. Salivary morbidity and quality of life following radioactive iodine for well-differentiated thyroid cancer. Otolaryngol Head Neck Surg 2013;148:746-52. official journal of American 
Academy of Otolaryngology-Head and Neck Surgery.

[76] Almeida JP, Vartanian JG, Kowalski LP. Clinical predictors of quality of life in patients with initial differentiated thyroid cancers. Arch Otolaryngol Head Neck Surg 2009;135:342-6.

[77] Goswami S, Peipert BJ, Mongelli MN, et al. Clinical factors associated with worse quality-of-life scores in United States thyroid cancer survivors. Surgery 2019;166:69-74.

[78] Jeong SY, Kim HW, Lee SW, et al. Salivary gland function 5 years after radioactive iodine ablation in patients with differentiated thyroid cancer: direct comparison of pre- and postablation scintigraphies and their relation to xerostomia symptoms. Thyroid 2013;23:609-16. official journal of the American Thyroid Association.

[79] Bhayani MK, Acharya V, Kongkiatkamon S, et al. Sialendoscopy for patients with radioiodine-induced sialadenitis and xerostomia. Thyroid 2015;25: 834-8. official journal of the American Thyroid Association.

[80] Sawka AM, Thabane L, Parlea L, et al. Second primary malignancy risk afte radioactive iodine treatment for thyroid cancer: a systematic review and meta-analysis. Thyroid 2009;19:451-7.

[81] Iyer NG, Morris LG, Tuttle RM, et al. Rising incidence of second cancers in patients with low-risk (T1N0) thyroid cancer who receive radioactive iodine therapy. Cancer 2011;117:4439-46.

[82] Rubino C, de Vathaire F, Dottorini ME, et al. Second primary malignancies in thyroid cancer patients. Br J Canc 2003;89:1638-44.

[83] American Thyroid Association Guidelines Taskforce on Thyroid N, Differentiated Thyroid C, Cooper DS, et al. Revised American Thyroid Association management guidelines for patients with thyroid nodules and differentiated thyroid cancer. Thyroid 2009;19:1167-214. official journal of the American Thyroid Association.

[84] Verburg FA, Aktolun C, Chiti A, et al. Why the European Association of Nuclear Medicine has declined to endorse the 2015 American Thyroid Association management guidelines for adult patients with thyroid nodules and differentiated thyroid cancer. Eur J Nucl Med Mol Imaging 2016;43:1001-5.

[85] Filetti S, Durante C, Hartl D, et al. Thyroid cancer: ESMO Clinical Practice Guidelines for diagnosis, treatment and follow-up. Ann Oncol 2019. official journal of the European Society for Medical Oncology.

[86] Haymart MR, Banerjee M, Stewart AK, et al. Use of radioactive iodine for thyroid cancer. Jama 2011:306:721-8.

[87] Park KW, Wu JX, Du L, et al. Decreasing use of radioactive iodine for low-risk thyroid cancer in California, 1999 to 2015. J Clin Endocrinol Metab 2018;103:
1095-101.

[88] Hartl DM, Leboulleux S, Al Ghuzlan A, et al. Optimization of staging of the neck with prophylactic central and lateral neck dissection for papillary thyroid carcinoma. Ann Surg 2012;255:777-83.

[89] Amit M, Boonsripitayanon M, Zafereo ME. ASO author reflections: strap muscle invasion does not influence recurrence and survival in patients with differentiated thyroid cancer. Ann Surg Oncol 2018;25:892-3.

[90] Maniakas A, Davies L, Zafereo ME. Thyroid disease around the world. Otolaryngol Clin N Am 2018:51:631-42.

[91] Bresner L, Banach R, Rodin G, et al. Cancer-related worry in Canadian thyroid cancer survivors. J Clin Endocrinol Metab 2015;100:977-85.

[92] Goswami S, Mongelli M, Peipert BJ, et al. Benchmarking health-related quality of life in thyroid cancer versus other cancers and United States normative data. Surgery 2018;164:986-92.

[93] Hedman C, Strang P, Djarv T, et al. Anxiety and fear of recurrence despite a good prognosis: an interview study with differentiated thyroid cancer patients. Thyroid 2017;27:1417-23.

[94] Williamson AG, Wilmot V, Ntala C, et al. Differentiated thyroid cancer: a retrospective evaluation of the impact of changes to disease management guidelines on patients in South East Scotland. The Surgeon 2019;17:73-9. journal of the Royal Colleges of Surgeons of Edinburgh and Ireland.

[95] Kluijfhout WP, Pasternak JD, Lim J, et al. Frequency of high risk characteristics requiring total thyroidectomy for $1-4 \mathrm{~cm}$ well differentiated thyroid cancer. Thyroid 2016.

[96] Sawant R, Hulse K, Sohrabi S, et al. The impact of completion thyroidectomy. Eur J Surg Oncol 2019;45:1171-4. the journal of the European Society of Surgical Oncology and the British Association of Surgical Oncology.

[97] De Jong SA, Demeter JG, Lawrence AM, et al. Necessity and safety of completion thyroidectomy for differentiated thyroid carcinoma. Surgery 1992:112:734-7. discussion 7-9.

[98] Momesso DP, Vaisman F, Yang SP, et al. Dynamic risk stratification in patients with differentiated thyroid cancer treated without radioactive iodine. J Clin Endocrinol Metab 2016;101:2692-700.

[99] Nixon IJ, Wang LY, Ganly I, et al. Outcomes for patients with papillary thyroid cancer who do not undergo prophylactic central neck dissection. Br J Surg 2016;103:218-25.

[100] Al-Qurayshi Z, Robins R, Hauch A, et al. Association of surgeon volume with outcomes and cost savings following thyroidectomy: a national forecast. JAMA Otolaryngol Head Neck Surg 2016;142:32-9. 